\title{
Arsenic inhibition of telomerase transcription leads to genetic instability
}

\author{
Wen-Chien Chou, ${ }^{1}$ Anita L. Hawkins, ${ }^{2}$ John F. Barrett, ${ }^{3}$ Constance A. Griffin, $, 2,4$ \\ and Chi V. Dang $1,3,4$
}

${ }^{1}$ Program in Human Genetics and Molecular Biology,

${ }^{2}$ Department of Pathology,

${ }^{3}$ Department of Medicine, and

${ }^{4}$ Johns Hopkins Oncology Center, Johns Hopkins University School of Medicine, Baltimore, Maryland, USA

Address correspondence to: Chi V. Dang, Room 1025, Ross Research Building,

720 Rutland Avenue, Baltimore, Maryland 21205, USA.

Phone: (410) 955-2773; Fax: (410) 955-0185; E-mail: cvdang@jhmi.edu.

Received for publication August 27, 2001, and accepted in revised form September 27, 2001.

Arsenic is effective in the treatment of acute promyelocytic leukemia. Paradoxically, it is also carcinogenic. In the process of elucidating a mechanism of arsenic resistance in a leukemia cell line, NB4, we discovered that arsenic exposure causes chromosomal abnormalities, with a preponderance of end-to-end fusions. These chromosomal end fusions suggested that telomerase activity may be inhibited by arsenic. We found that arsenic inhibits transcription of the $b T E R T$ gene, which encodes the reverse transcriptase subunit of human telomerase. This effect may in part be explained by decreased c-Myc and Sp1 transcription factor activities. Decreased telomerase activity leads to chromosomal end lesions, which promote either genomic instability and carcinogenesis or cancer cell death. These phenomena may explain the seemingly paradoxical carcinogenic and antitumor effects of arsenic.

J. Clin. Invest. 108:1541-1547 (2001). DOI:10.1172/JCI200114064.

\section{Introduction}

Hippocrates' medicinal repertoire over 2000 years ago included arsenic, which was also recommended as an antileukemic agent in Sir William Osler's 1892 first edition of The Principles and Practice of Medicine. Although arsenic has long been regarded as a carcinogen and toxin (1-4), clinical studies in China, subsequently confirmed elsewhere, demonstrate the dramatic effect of arsenic trioxide in the therapy of acute promyelocytic leukemia (APL) (5-8).

APL accounts for $10 \%$ of adult acute myeloid leukemia and presents with coagulopathy and a specific chromosomal translocation, $\mathrm{t}(15 ; 17)$, that results in the fusion protein PML-RAR $\alpha$ (9). The prognosis of APL dramatically improved after introduction of alltrans retinoic acid, which leads to as high as a $95 \%$ remission induction $(9,10)$. However, emergence of resistance to all-trans retinoic acid is rapid and salvage therapy is needed.

Arsenic trioxide has proven to be effective against APL that is refractory to all-trans retinoic acid and conventional chemotherapy (5-8). Although the exact mechanism of arsenic efficacy remains unknown, it appears to exert its antitumor effects by activating apoptosis $(5,7)$. Some reports attributed its effect to induction of reactive oxygen species (11-14). Arsenic also can induce degradation of the PML-RAR $\alpha$ fusion protein, and this effect was thought to underlie arsenic anti-APL activity $(15,16)$. However, since the presence of PML-RAR $\alpha$ fusion protein is neither necessary nor sufficient for the efficacy of arsenic $(8,17)$ and arsenic induces apoptosis in other cancer cell lines lacking PML-RAR $\alpha$ (17), alternative mechanisms must be considered.

In this report, we find that arsenic potently inhibits the transcription of the reverse transcriptase subunit of the human telomerase gene ( $h T E R T$ ). Telomerase is an enzyme that maintains the length of chromosomal ends or telomeres, which otherwise would progressively shorten after each cell division (18). Although not universal, telomerase activity is frequently found in advanced cancer cells and is important for continuous cancer cell proliferation $(19,20)$. Since most cancer cells lacking telomerase showed sluggish growth and death, telomerase has become an attractive target for anticancer treatment $(21,22)$. There is, however, a dearth of small-molecule chemotherapeutics that specifically inhibit telomerase. Interestingly, cells lacking telomerase are paradoxically prone to genomic instability and carcinogenesis (23-26). In this report, we describe arsenic as a potent inhibitor of $b T E R T$ expression, and this effect appears at doses comparable to or lower than those clinically achievable. The effect may result from a diminished level or function of two transcription factors, $\mathrm{c}-\mathrm{Myc}$ and Sp1, which are both important for bTERT expression $(27,28)$.

\section{Methods}

Cell culture and reagents. All cell lines were cultured in 5\% $\mathrm{CO}_{2}$ at $37^{\circ} \mathrm{C}$ in DMEM high-glucose medium except for NB4 (a gift of Robert Redner, University of Pittsburgh, Pittsburgh, Pennsylvania, USA), which was 
maintained in RPMI1640. The medium was supplemented with $10 \%$ FBS and 100 units/ml of penicillin plus $100 \mu \mathrm{g} / \mathrm{ml}$ streptomycin. Arsenic trioxide, 3-[4,5dimethylthiazol-2-yl]-2,5-diphenyltetrazolium bromide (MTT), and actinomycin D were purchased from Sigma Chemical Co. (St. Louis, Missouri, USA).

MTT cytotoxicity assay. The viability of cells plated on culture dishes was measured by adding MTT reagent, which was dissolved in PBS, to a final concentration of $0.5 \mathrm{mg} / \mathrm{ml}$. After 4 hours of incubation, cells were solubilized in $0.5 \mathrm{~N} \mathrm{HCl}, 5 \%$ Triton X-100, and $45 \% 2$ propanol (final concentration). The intensity of dissolved formazan crystal was measured at $590 \mathrm{~nm}$.

Cytogenetic and telomere fluorescence in situ bybridization studies. Preparations for cytogenetic analysis were made by exposing the cell lines to colcemid at $5 \mathrm{ng} / \mathrm{ml}$ for $16-$ 18 hours to accumulate metaphases, followed by hypotonic treatment at $37^{\circ} \mathrm{C}$ for 30 minutes, and fixation in 3:1 methanol/glacial acetic acid. Air-dried slides were made and solid-stained for analysis of breakage and fusion rearrangements. Where sufficient material was available, a slide was also G-banded by standard techniques to examine the karyotype of the cell lines, and to identify chromosomes involved in fusion events. Ten to twenty well-spread metaphases were counted and the number of dicentrics, tricentrics, rings, and acentric fragments was recorded. Less commonly observed events, such as chromosomal breakage, multicentric chromosomes, or chromosome end-clusters, were also recorded. Fusion events were calculated as sum of numbers of dicentrics, $2 \times$ tricentrics, and $3 \times$ quadricentrics. Fluorescence in situ hybridization (FISH) was performed on metaphase spread using the peptide nucleic acid-telomere probe (Applied Biosystems, Foster City, California, USA; kindly provided by Carol Greider, the Johns Hopkins University, Baltimore, Maryland, USA) according to the manufacturer's instructions. A normal lymphocyte metaphase control was included on the same slide with the arsenic-treated cells.

Telomerase activity assay. Telomere repeat amplification protocol (TRAP) was implemented with a TRAPeze kit according to the manufacturer's instructions (Intergen Co., Purchase, New York, USA). Five hundred cells were assayed in each sample.

Telomere length measurement. Genomic DNA was digested with RsaI and Hinfl, followed by separation on $0.6 \%$ agarose gel and hybridization with (TTAGGG) 6 probes.

Real-time PCR. Real-time PCR was performed using 7700 model ABI PRISM sequence detector (Applied Biosystems). The sequences of the forward primer, reverse primer, and TaqMan probe for $b T E R T$ were $5^{\prime}$ TACGTCGTGGGAGCCAGAAC- $3^{\prime}, 5^{\prime}$-CCTTCACCCTCGAGGTGAGA-3' ${ }^{\prime}$, and $5^{\prime}$-TTCCGCAGAGAAAAGAGGGCCGA- ${ }^{\prime}$, respectively. The sequences of the forward primer, reverse primer, and TaqMan probe for human c-Myc were $5^{\prime}$-TCAAGAGGTGCCACGTCTCC-3', $5^{\prime}$-TCTTGGCAGCAGGATAGTCCTT- $3^{\prime}$, and 5'-CAGCACAACTACGCAGCGCCTCC-3', respectively. One hundred nanograms total RNA from NB4 cells and $500 \mathrm{ng}$ total
RNA from other cell lines were used in $25 \mu \mathrm{l}$ reaction mixture per well using TaqMan one-step RT-PCR kit (Applied Biosystems). Internal control of human phosphoprotein (buPo) or $\beta$-actin tagged with VIC dye (Applied Biosystems) was included in every well as control. The reaction conditions were $55^{\circ} \mathrm{C}$ for 30 minutes, followed by $95^{\circ} \mathrm{C}$ for 10 minutes, and 40 cycles of $95^{\circ} \mathrm{C}$ for 15 seconds and $60^{\circ} \mathrm{C}$ for 1 minute.

Nuclear run-on reaction. The experiment was performed as described earlier (29). Twenty-five million freshly isolated nuclei from NB4 cells either treated or untreated with $0.75 \mu \mathrm{M}$ arsenic for 8 days were used in the reaction. After 20 minutes of in vitro transcription reaction at $27^{\circ} \mathrm{C},\left[{ }^{32} \mathrm{P}\right]$ UTP-labeled RNA from these two populations was treated with DNase I and proteinase $\mathrm{K}$, followed by phenol-chloroform extraction. RNA with an equal amount of radioactivity was added onto nylon membranes slot-blotted with an excess amount of cDNA fragments of $b T E R T, \mathrm{c}-M y c$, and $b u P o$. After 40 hours of hybridization at $42^{\circ} \mathrm{C}$, the blots were washed and developed.

Plasmid construction and transfection. The insert of PSG5$\mathrm{Sp} 1$ is a 3.1-kb MfeI-SalI fragment of pPac-Sp1 (30). pSG5-Luc was created by subcloning a 1.7-kb HindIIIXbaI fragment of $\mathrm{Luc}^{+}$from pGL3-Basic vector (Promega Corp., Madison, Wisconsin, USA). pMT-Luc and PMT-Sp1 were created by subcloning a 1.7-kb KpnIXbaI $L u c^{+}$fragment from pGL3-Basic and a 3.4-kb MfeIHindIII Sp1 fragment from pPac-Sp1 into pMT-CB6 ${ }^{+}$ vector, respectively. pHTR-Luc, which contained an 800bp promoter region of $h T E R T$ fused with luciferase gene, is a gift from Riccardo Dalla-Favera (Columbia University, New York, New York, USA) (28). One hundred thousand NIH-3T3 cells per well were plated into six-well plates 16 hours before transfection. Two micrograms total plasmid was transfected per well using SuperFect reagent (QIAGEN Inc., Valencia, California, USA). Fresh medium with or without $5 \mu \mathrm{M}$ arsenic was added 3 hours later. Luciferase activity was determined 44 hours after transfection.

Gel shift assay. Nuclear lysate of NB4 cells either treated or untreated with $0.75 \mu \mathrm{M}$ arsenic for 8 days was extracted and dissolved in $50 \mathrm{mM}$ Hepes ( $\mathrm{pH} 7.8$ ), 50 $\mathrm{mM} \mathrm{KCl}, 400 \mathrm{mM} \mathrm{NaCl}, 0.1 \mathrm{mM}$ EDTA, 10\% glycerol, $3 \mathrm{mM}$ DTT, and protease inhibitor made from $1 \mathrm{com}-$ plete protease inhibitor cocktail tablet (Roche Molecular Biochemicals, Indianapolis, Indiana, USA) in $50 \mathrm{ml}$ reaction. In $10 \mu \mathrm{l}$ of binding reaction, $2.5 \mu \mathrm{l}$ of nuclear extract $(0.625 \mu \mathrm{g}$ for SP1 and $2.5 \mu \mathrm{g}$ for Oct-1) was incubated with binding buffer containing $4 \%$ glycerol, $1 \mathrm{mM} \mathrm{MgCl}_{2}, 0.5 \mathrm{mM}$ EDTA, $0.5 \mathrm{mM}$ DTT, $5 \mathrm{mM}$ $\mathrm{NaCl}, 10 \mathrm{mM}$ Tris- $\mathrm{Cl}$ (pH 7.5), $0.02 \mathrm{~N} \mathrm{NaOH}$, and 0.5 $\mu \mathrm{g}$ poly $(\mathrm{dI}-\mathrm{dC}) \cdot$ poly $(\mathrm{dI}-\mathrm{dC})$ with or without corresponding antibody (Santa Cruz Biotechnology Inc., Santa Cruz, California, USA) for 30 minutes on ice. End-labeled oligonucleotide was then added and incubated on ice for another 30 minutes before loading on $5 \%$ nondenaturing polyacrylamide gel. The sequences of oligonucleotide for $\mathrm{Sp} 1$ and Oct-1 binding sites were 
5'-CTGCGGGGCGGGGCAGACCCCGCCCGTCTGACG-3' (31) and 5'-TGTCGAATGCAAATCACTAGAA-3' (Santa Cruz Biotechnology Inc.), respectively.

\section{Results}

Arsenic causes chromosomal end-to-end fusion and diminishes telomerase activity. During our screening for arsenicresistant NB4 clones, cells that remained after a 3week exposure to $0.75 \mu \mathrm{M}$ arsenic dramatically enlarged. No clones out of $2 \times 10^{8}$ cells survived 1 month of continuous exposure to arsenic at this dose. Karyotyping of these arsenic-treated, morphologically abnormal, enlarged cells showed striking chromosomal end-to-end fusion (Figure 1, a and b). From 80 karyotypes, we observed more prominent polyploidy in 32 cells and an average of 2.4 fusion events per cell. The chromosomal fusions are associated with attrition of telomeres, since no signal was seen at the fusion junction in dicentric chromosomes by FISH using a telomerespecific probe (Figure 1d). In addition, Southern blot analysis of NB4 cells reveals a shortening of telomeres with exposure to arsenic (Figure 1c). By contrast, untreated NB4 cells showed the characteristic $\mathrm{t}(15 ; 17)$ chromosomal translocation without end-to-end fusions or breakage and had a consistent near-triploid range of $N=75-80$. Further cytogenetic analysis of NB4 cells and two of its subclones exposed to various doses of arsenic $(0.75 \mu \mathrm{M}$ to $1.0 \mu \mathrm{M})$ for 2 weeks showed a doserelated increase of chromosomal end-to-end fusions (data not shown).

Chromosomal end-to-end fusions have been observed in telomerase-deficient murine cells (23). To determine the basis for the generation of endto-end chromosomal fusions in our experiment, we measured telomerase activity using the TRAP assay in cells exposed to arsenic (19). Telomerase activity was severely diminished in NB4 cells after 8 days of $0.75 \mu \mathrm{M}$ arsenic treatment (Figure 1e), although significant numbers of fusion chromosomes were not observed until 2-3 weeks (data not shown). To determine whether arsenic could inhibit telomerase activity directly in vitro, $10 \mu \mathrm{M}$ arsenic was added to the TRAP reaction mixture; no effect on telomerase activity was observed (data not shown).

Arsenic decreases $b T E R T$ TRNA levels in different cell types. The suppression of telomerase activity by arsenic correlated with a dramatic decrease in hTERT $\mathrm{mRNA}$ and protein, indicating that arsenic inhibits the expression of $b T E R T$ (Figure 2, a and b). Moreover, there is a dose-related suppression of hTERT $\mathrm{mRNA}$ expression as measured by real-time PCR (Figure 3a). In contrast to $b T E R T$ mRNA levels, the RNA component of telomerase bTER was elevated in the presence of arsenic (Fig. 2a).

To determine whether the inhibition of bTERT expression is specific to arsenic, two chemotherapeutic agents, vincristine and doxorubicin, with dif- ferent well-documented mechanisms of cytotoxicity were tested at concentrations that maintain sufficient cell viability so that cell death is not a confounding factor. Treatment of NB 4 cells for 48 hours with $0.075 \mathrm{nM}$ vincristine, $25 \mathrm{nM}$ doxorubicin, or $0.75 \mu \mathrm{M}$ arsenic resulted in about $80 \%$ viability (determined by MTT assay), as compared with untreated control (data not shown). While the cells treated with vincristine or dox-

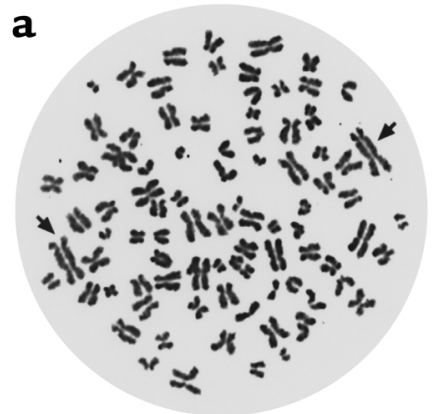

b
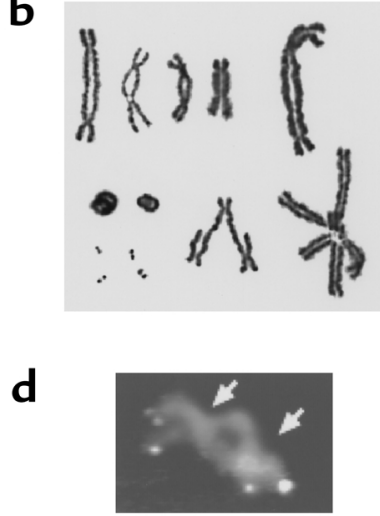

c

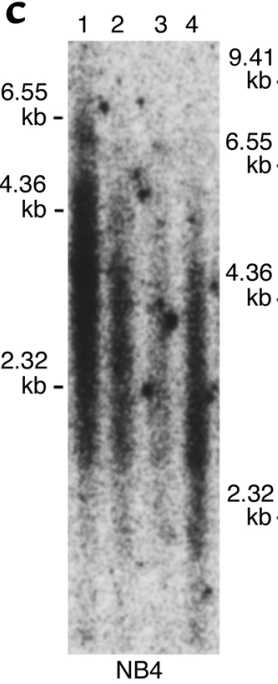

$\begin{array}{lll}5 & 6 & 7\end{array}$
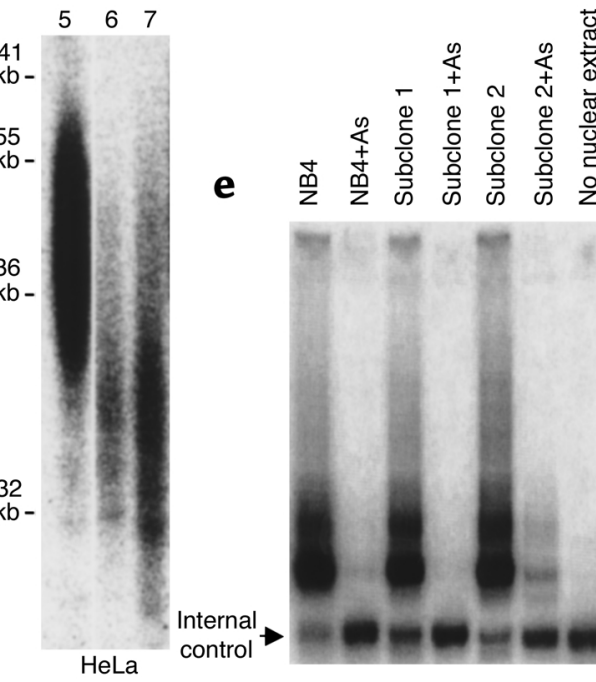

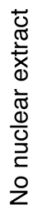

Figure 1

Chromosomal abnormalities and telomerase activity of NB4 cells treated with arsenic. (a) A representative entire metaphase from NB4 cells treated with arsenic at $0.75 \mu \mathrm{M}$ for 3 weeks. The arrows indicate dicentric fusion chromosomes. (b) Representative dicentric chromosomal fusions as well as other abnormal fused chromosomes and fragments from cells treated with arsenic at $0.75 \mu \mathrm{M}$ for 3 weeks. (c) Southern blot of digested genomic DNA from NB4 (left) and HeLa cells (right) showed decreased telomere length after arsenic exposure. Lane 1: untreated NB4 cells; lanes 2-4: 0.25 $\mu \mathrm{M}$ arsenic for 4, 5, and 6 weeks, respectively. Lane 5: untreated HeLa cells; lanes 6 and 7: $1 \mu \mathrm{M}$ arsenic for 3 and 4 weeks, respectively. (d) Dicentric chromosome after FISH with a telomere-specific probe. Arrows indicate centromeres. FISH signals are clearly visible at both ends of the fusion chromosome. Among 16 fusions studied, no hybridization is seen between the centromeres where fusion occurred. In contrast, 95-97\% of chromosome ends of a normal lymphocyte control display intense signal (data not shown). (e) Telomerase activity of NB4 cells treated with arsenic. Pooled NB4 cells and independently isolated subclones showed dramatically decreased telomerase activity after 8 days of $0.75 \mu \mathrm{M}$ arsenic. The internal control represents a band that should appear in every TRAP assay to ensure a reliable $\mathrm{PCR}$ reaction. Because of competition of components, higher telomerase activities result in fainter internal control bands. 


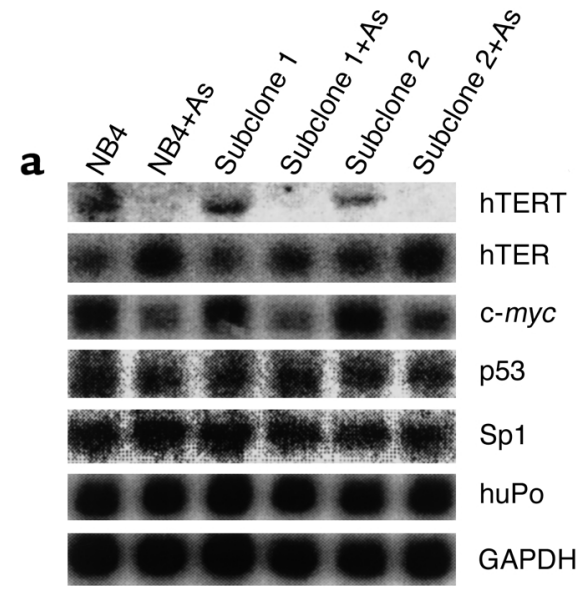

b

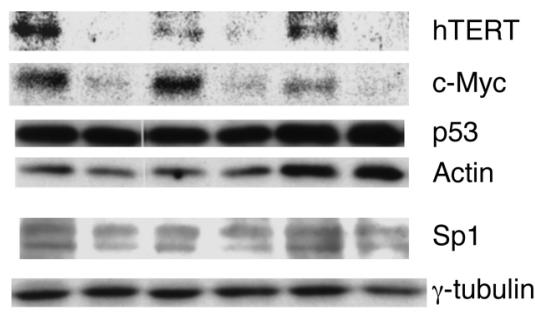

orubicin did not have significant changes in hTERT mRNA level as measured by real-time PCR, arsenic treatment resulted in a marked decrease in $b T E R T$ expression (Figure 3b). Although most cells died at a higher concentration of vincristine $(0.25 \mathrm{nM})$, , bTERT mRNA levels remained unsuppressed (data not shown). Furthermore, treatment of NB4 cells at concentrations of arsenic as low as $0.1 \mu \mathrm{M}$ for 12 days also significantly suppressed $h T E R T$ expression (Figure 3a), demonstrating the potency of arsenic in inhibiting telomerase. To determine whether arsenic could inhibit telomerase

\section{Figure 2}

mRNA and protein levels of $h T E R T, h T E R$, c-myc, $p 53$, and Sp1 in NB4 cells after arsenic treatment. (a) Northern blot analysis shows diminished $h T E R T$ and c-myc mRNA after 8 days of $0.75 \mu \mathrm{M}$ arsenic treatment. By contrast, the RNA component of telomerase, $h T E R$, is elevated in arsenic-treated samples. Levels of $p 53$ and Sp1 mRNA were unchanged by arsenic. Human phosphoprotein (huPo) and GAPDH served as loading controls. (b) Immunoblotting shows a corresponding decrease in protein levels of hTERT and c-Myc after arsenic treatment, but $\mathrm{p} 53$ and $\mathrm{Sp} 1$ protein levels remained unaltered. Actin and $\gamma$-tubulin served as loading controls.

expression in other cell lines, HeLa (cervical cancer), HepG2 (hepatoma), LoVo (colon cancer), and MCF7 (breast cancer) cells were tested. After 14 days of exposure to $2 \mu \mathrm{M}$ arsenic, all cell lines, except for HepG2 (data not shown), had decreased $b T E R T$ expression (Figure $3 c)$. In contrast to HepG2 cells that were inhibited by $30 \%$ after 1 week of $2 \mu \mathrm{M}$ arsenic exposure, there was about $80 \%$ growth inhibition in HeLa, LoVo, and MCF7 (determined by MTT assay; data not shown). It is notable that in addition to NB4 cells, arsenic also shortens telomeres in HeLa cells treated with arsenic (Figure 1c). These observations suggest a relationship between telomerase inhibition and viability of these cell lines. Hence, inhibition of $b T E R T$ expression is relatively specific to arsenic, can be seen in cancer cell lines other than APL, and is not simply due to cell death.

Arsenic inbibits bTERT transcription. Because arsenic inhibits $b T E R T$ expression, we sought to determine whether arsenic inhibits transcription of $b T E R T$ or shortens the half-life of the $b T E R T$ mRNA. The half-life of $h T E R T$ mRNA is relatively long (4 hours) and is not shortened by exposure of cells to arsenic (Figure 4a). Though bTERT expression is low, especially after arsenic treatment, the cycles of threshold $\left(C_{t}\right)$ are still within the linear range of the standard curve of real-

\section{Figure 3}

Arsenic specifically suppresses $h T E R T$ mRNA levels independent of cell type. The expression of hTERT and c-myc was measured by real-time PCR and normalized to actin in $\mathbf{b}$ and human phosphoprotein in $\mathbf{a}, \mathbf{c}$, and d. hTERT mRNA levels are expressed as percent of untreated control. (a) Arsenic diminished hTERT mRNA expression in a dose-dependent fashion. Experiments were performed after 12 days of arsenic exposure. (b) Two days of arsenic $(0.75 \mu \mathrm{M})$ but not vincristine (Vin; $0.075 \mathrm{nM}$ ) or doxorubicin (Dox; $50 \mathrm{nM}$ ) diminishes hTERT mRNA levels. (c) Cell lines other than NB4 also had decreased hTERT mRNA levels after arsenic treatment. NB4 cells were especially sensitive as $0.75 \mu \mathrm{M}$ for 8 days had resulted in more than $98 \%$ inhibition of hTERT expression. The other cell lines were treated with $2 \mu \mathrm{M}$ arsenic for 14 days. (d) c-myc expression was also decreased in all four cell lines with arsenic exposure. a

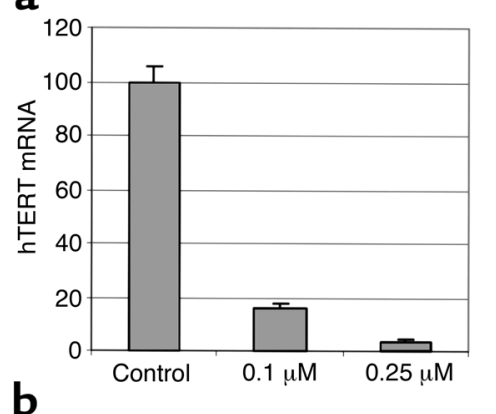

b

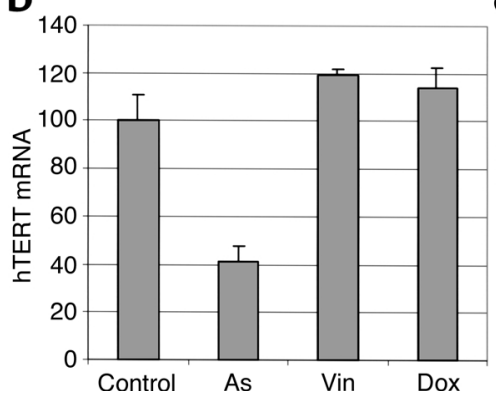

C
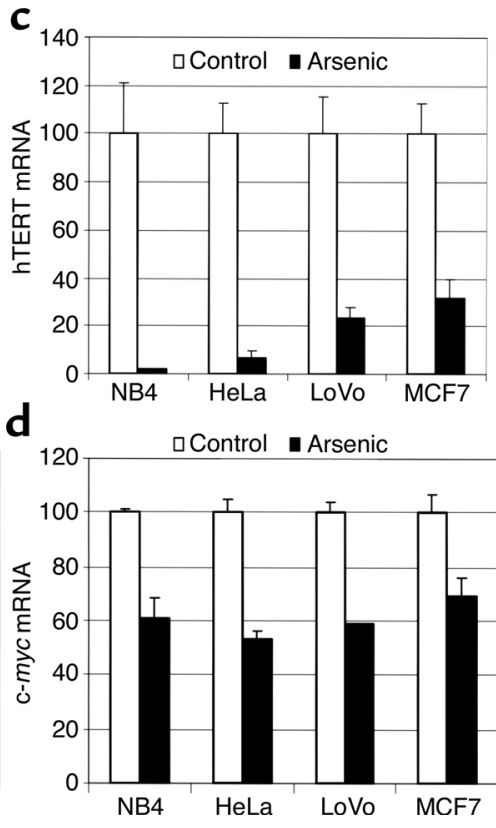


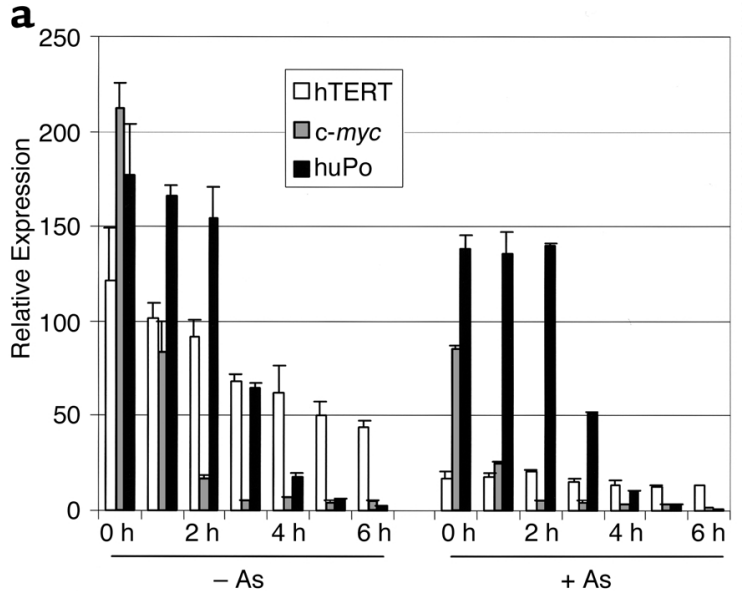

b

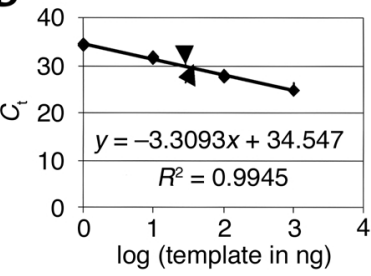

C

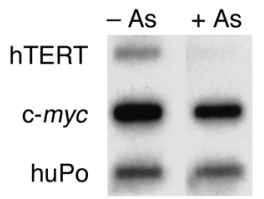

time PCR, assuring the validity of the measurement (Figure 4b). Furthermore, nuclear run-on studies demonstrated severely diminished transcription of hTERT in arsenic-treated NB4 cells as compared with control cells (Figure 4c). These studies indicate that arsenic inhibits $b T E R T$ at the transcription level.

Arsenic inbibits c-Myc transcription and Sp1 DNA binding activity. Because the $b T E R T$ promoter contains binding sites for c-Myc and Sp1 (32), and these transcription factors can cooperatively activate $b T E R T$ expression (27), we tested whether these transcription factors were affected in arsenic-treated cells. c-myc mRNA and protein levels decreased in arsenic-treated NB4 cells (Figure 2, a and b). We also observed a decrease in c-myc RNA levels with arsenic exposure in the various cell lines tested, except for HepG2 (Figure 3d and data not shown). Nuclear run-on and RNA stability studies indicate that c-myc transcription is also inhibited by arsenic (Figure 4, a and c). By contrast, Sp1 mRNA and protein were not changed by arsenic exposure (Figure 2, a and

\section{Figure 5}

Arsenic inhibits Sp1 function in hTERT transcription. (a) Cotransfection with pSG5-Sp1 and the reporter, pHTR-Luc, activates $h T E R T$ transcription fourfold compared with pHTR-Luc only. A 44-hour arsenic $(5 \mu \mathrm{M})$ exposure significantly inhibits PHTR-Luc alone and the combination of pSG5-Sp1 and pHTR-Luc. The inherent activities of both the hTERT promoter (reporter plasmid only) and pSG5-Luc without arsenic were set as 1.0. While arsenic inhibited pSG5-Sp1 activation of the hTERT promoter, it could not inhibit pSG5-Luc. (b) Cotransfection with pMT-Sp1 and pHTR-Luc recapitulates the result in $\mathbf{a}$. The inherent activities of both the hTERT promoter and pSG5Luc without arsenic were set as 1.0. (c) Sp1 (left panel) but not Oct1 (right panel) DNA binding activity is diminished by $0.75 \mu \mathrm{M}$ arsenic exposure for 8 days. SS, supershift band; FP, free probe.

\section{Figure 4}

Arsenic inhibits the transcription of hTERT. (a) Half-life of hTERT mRNA is unaltered by arsenic. Control and arsenic-exposed $(0.75 \mu \mathrm{M}$ arsenic for 2 days) NB4 cells were treated with actinomycin D ( 5 $\mu \mathrm{g} / \mathrm{ml})$. RNA was collected at the time points indicated and real-time PCR was performed to detect the expression of hTERT, c-myc, and huPo. Both c-myc and huPo mRNA decayed in control and arsenictreated samples and thus served as positive controls for this assay. hTERT mRNA decay was not increased by arsenic. (b) hTERT expression in control (lower arrowhead) and arsenic-treated (upper arrowhead) samples was well within the linear range on the standard curve of real-time PCR. (c) Nuclear run-on reaction showed diminished transcription of hTERT in NB4 cells treated with $0.75 \mu \mathrm{M}$ for 8 days. c-myc transcription rate also decreased to $40 \%$. huPo served as control.

b). Another candidate for investigation is p53, which sequesters Sp1 and in turn inhibits $b T E R T$ expression (33). However, in our study, arsenic did not affect $p 53$ mRNA or protein levels (Figure 2 , a and b).

Because Sp1 activates the transcription of both c-myc and $h T E R T$, we sought to determine whether Sp1 activity could be inhibited by arsenic. We performed luciferase assays using NIH-3T3 cells cotransfected with pSG5-Sp1 and a reporter plasmid, pHTR-Luc, which contains an 800-bp $b T E R T$ promoter with c-Myc and Sp1 binding sites in it. Overexpression of Sp1 increased $b T E R T$ promoter activity fourfold (Figure $5 \mathrm{a}$ ). Arsenic significantly inhibited the induction of $b T E R T$ promoter by Sp1 (Figure 5a). This inhibition was not due to an effect of arsenic on the SV40 early promoter
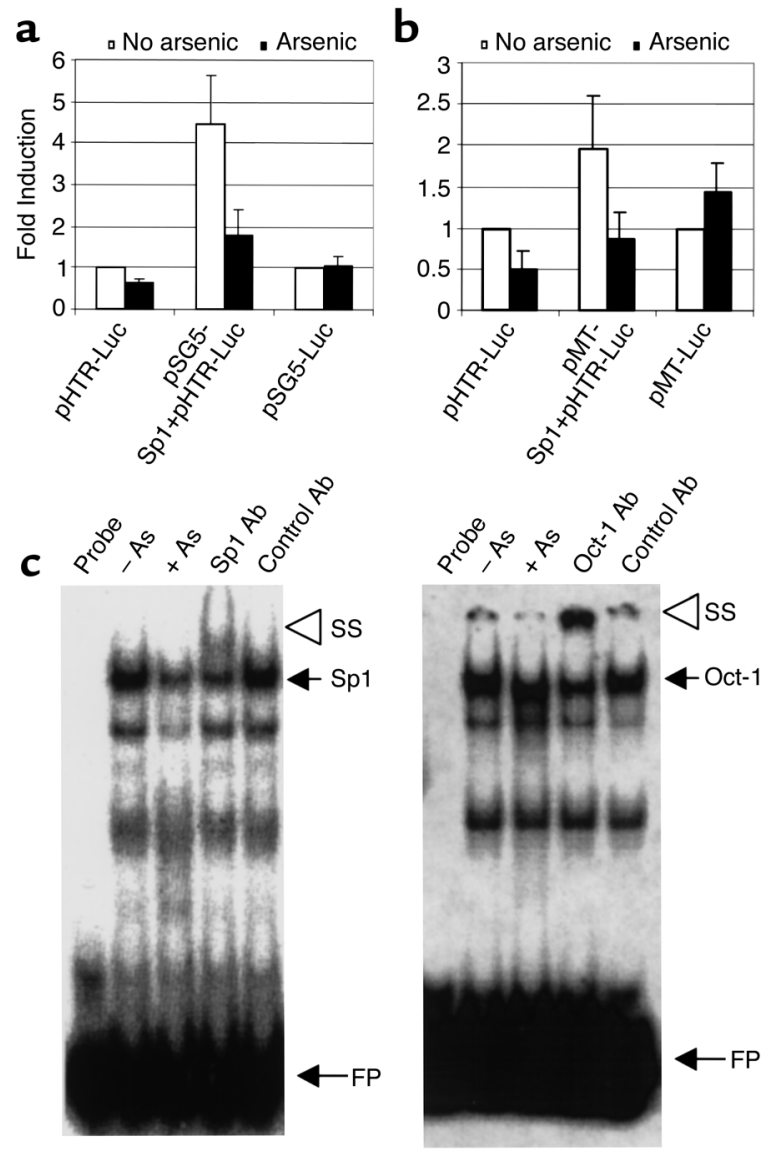
in PSG5-Sp1, since arsenic did not inhibit the activity of pSG5-Luc (Figure 5a). To further substantiate these observations, we have also used a plasmid pMT-Sp1 with the arsenic-inducible sheep metallothionein promoter driving Sp1 expression. In this case, we circumvented any potential inhibition of the promoter by arsenic, and we again observed an arsenic-dependent inhibition of Sp1 induction of the hTERT promoter (Figure 5b). Hence, arsenic could inhibit Sp1-mediated DTERT transcription at a functional level.

We further observed that Sp1 DNA binding activity was decreased in arsenic-treated cells, as determined by gel shift assays (Figure $5 c$, left panel). The transcription factor Oct-1, on the other hand, was minimally affected by arsenic (Figure $5 c$, right panel), indicating that arsenic exposure does not cause a general decline in transcription factor function. Sp1 DNA binding activity, however, was not inhibited in vitro through the direct addition of arsenic to gel shift assays (data not shown). These observations suggest that arsenic inhibits Sp1 indirectly, perhaps through the generation of reactive oxygen species, which in turn oxidizes and inactivates Sp1 (34). We surmise that together with the reduction in c-myc gene expression, which also depends on Sp1 activity (35), decreased Sp1 activity contributes to the marked decrease in $b T E R T$ transcription.

\section{Discussion}

Pharmacokinetic studies showed that plasma arsenic levels peaked around $7 \mu \mathrm{M}$ and then dropped to less than $1 \mu \mathrm{M}$ after daily intravenous infusion into human subjects (6). These levels are comparable to those used in our in vitro studies, which demonstrate a dramatic inhibition of $b T E R T$ expression by arsenic. High levels of arsenic ( $10 \mu \mathrm{M}$ for 2 days), however, are thought to induce reactive oxygen species that in turn induce multilocus chromosomal deletion rather than end-to-end fusion $(13,14)$. Since chronic arsenic exposure and numerous cell doublings are required for telomere attrition, the cytotoxicity and multilocus deletion occurring after short-term exposure to high levels of arsenic are likely due to alternative mechanisms. Nevertheless, reactive oxygen species might play a role in inhibition of $h T E R T$ transcription because of its potential oxidative inactivation of Sp1 (34). While our findings suggest a role of $\mathrm{Sp} 1$ in the inhibition of bTERT expression, the fact that arsenic did not inhibit the SV40 minimal promoter, which contains several Sp1 sites, is seemingly contradictory. Because the SV40 minimal promoter is complex, we do not understand why diminished Sp1 activity would not affect the SV40 promoter in this context. Since we have not exhaustively examined the global effect of arsenic on gene expression, the inhibitory effect of arsenic on other genes may also contribute to the decrease in $\operatorname{LTERT}$ expression and telomere maintenance.

An important implication of our finding is that the inhibition of $h T E R T$ by arsenic may explain the seemingly paradoxical role of arsenic in tumorigenesis and antitumor therapy. Likewise, telomerase plays a paradoxical role in tumorigenesis. For most advanced tumors, telomere maintenance is essential for continued proliferation and avoidance of senescence $(21,22)$. Similarly, the importance of telomerase activity in tumorigenesis is also recapitulated in vivo in telomerase-deficient mice, which have decreased propensity for the tumor development in the $p 16 / p 19^{A R F}$-null background (36). For noncancerous cells, however, loss of telomeres could lead to genomic instability and cancer formation (23-26). Consistent with this observation is the increased tumorigenesis in mice deficient for both p53 and telomerase (37). In this case, loss of p53 suppresses apoptosis that is triggered by telomerase deficiency. While our observations suggest that inhibition of telomerase expression by arsenic contributes to chromosomal end-to-end fusions, there may be other mechanisms that contribute to these chromosomal abnormalities. It is unlikely, however, that loss of TRF2, which binds to and protects telomeres, could contribute to arsenic-induced end-to-end chromosomal fusions. Loss of TRF2 would lead to chromosomal end fusions, but in this case telomere length would not be affected. Both our FISH and Southern blot analyses indicate that arsenic shortens telomere length. Thus, inhibition of telomerase expression by arsenic may account for both its tumorigenic potential and its effectiveness as an antineoplastic agent.

\section{Acknowledgments}

This work was supported by NIH grant CA-51497. We thank R. Dalla-Favera, L. Gardner, C. Greider, A. Lee, Q. $\mathrm{Li}$, and $\mathrm{R}$. Redner for comments and reagents.

1. Leonard, A., and Lauwerys, R.R. 1980. Carcinogenicity, teratogenicity and mutagenicity of arsenic. Mutat. Res. 75:49-62.

2. Hertz-Picciotto, I., Smith, A.H., Holtzman, D., Lipsett, M., and Alexeeff, G. 1992. Synergism between occupational arsenic exposure and smoking in the induction of lung cancer. Epidemiology. 3:23-31.

3. Chappell, W.R., et al. 1997. Inorganic arsenic: a need and an opportunity to improve risk assessment. Environ. Health Perspect. 105:1060-1067.

4. Kitchin, K.T. 2001. Recent advances in arsenic carcinogenesis: modes of action, animal model systems, and methylated arsenic metabolites. Toxicol. Appl. Pharmacol. 172:249-261.

5. Chen, G.Q., et al. 1997. Use of arsenic trioxide $\left(\mathrm{As}_{2} \mathrm{O}_{3}\right)$ in the treatment of acute promyelocytic leukemia (APL). I. $\mathrm{As}_{2} \mathrm{O}_{3}$ exerts dose-dependent dual effects on APL cells. Blood. 89:3345-3353.

6. Shen, Z.X., et al. 1997. Use of arsenic trioxide $\left(\mathrm{As}_{2} \mathrm{O}_{3}\right)$ in the treatment of acute promyelocytic leukemia (APL). II. Clinical efficacy and pharmacokinetics in relapsed patients. Blood. 89:3354-3360.

7. Shao, W., et al. 1998. Arsenic trioxide as an inducer of apoptosis and loss of PML/RAR $\alpha$ protein in acute promyelocytic leukemia cells. J. Natl. Cancer. Inst. 90:124-133.

8. Soignet, S.L., et al. 1998. Complete remission after treatment of acute promyelocytic leukemia with arsenic trioxide. N. Engl. J. Med. 339:1341-1348.

9. Warrell, R.P., De The, H., Wang, Z.Y., and Degos, L. 1993. Acute promyelocytic leukemia. N. Engl. J. Med. 329:177-189.

10. Fenaux, P., Chastang, C., Chomienne, C., and Degos, L. 1994. Tretinoin with chemotherapy in newly diagnosed acute promyelocytic leukaemia. European APL group. Lancet. 343:1033

11. Chen, Y.C., Lin-Shiau, S.Y., and Lin, J.K. 1998. Involvement of reactive oxygen species and caspase 3 activation in arsenite-induced apoptosis. J. Cell. Physiol. 177:324-333.

12. Ozaki, M., Deshpande, S.S., Angkeow, P., Suzuki, S., and Irani, K. 2000. Rac1 regulates stress-induced, redox-dependent heat shock factor activation. J. Biol. Chem. 275:35377-35383.

13. Hei, T.K., Liu, S.X., and Waldren, C. 1998. Mutagenicity of arsenic in mammalian cells: roles of reactive oxygen species. Proc. Natl. Acad. Sci. USA. 95:8103-8107. 
14. Liu, S.X., Athar, M., Lippai, I., Waldren, C., and Hei, T.K. 2000. Induction of oxyradicals by arsenic: implication for mechanism of genotoxicity. Proc. Natl. Acad. Sci. USA. 98:1643-1648.

15. Muller, S., Matunis, M.J., and Dejean, A. 1998. Conjugation with the ubiquitin-related modifier SUMO-1 regulates the partitioning of PML within the nucleus. EMBO J. 17:61-70.

16. Sternsdorf, T., et al. 1999. PIC-1/SUMO-1-modified PML-retinoic acid receptor $\alpha$ mediates arsenic trioxide-induced apoptosis in acute promyelocytic leukemia. Mol. Cell. Biol. 19:5170-5178.

17. Zhu, X.H., et al. 1999. Apoptosis and growth inhibition in malignant lymphocytes after treatment with arsenic trioxide at clinically achievable concentrations. J. Natl. Cancer Inst. 91:772-778.

18. Greider, C.W. 1996. Telomere length regulation. Annu. Rev. Biochem. 65:337-365

19. Kim, N.W., et al. 1994. Specific association of human telomerase activity with immortal cells and cancer. Science. 266:2011-2015.

20. Bryan, T.M., Englezou, A., Gupta, J., Bacchetti, S., and Reddel, R.R. 1995. Telomere elongation in immortal human cells without detectable telomerase activity. EMBO J. 14:4240-4248.

21. Zhang, X., Mar, V., Zhou, W., Harrington, L., and Robinson, M.O. 1999 Telomere shortening and apoptosis in telomerase-inhibited human tumor cells. Genes Dev. 13:2388-2399.

22. Hahn, W.C., et al. 1999. Inhibition of telomerase limits the growth of human cancer cells. Nat. Med. 5:1164-1170.

23. Rudolph, K.L., et al. 1999. Longevity, stress response, and cancer in aging telomerase-deficient mice. Cell. 96:701-712.

24. Hackett, J.A., Feldser, D.M., and Greider, C.W. 2001. Telomere dysfunction increases mutation rate and genomic instability. Cell. 106:275-286.

25. Romanov, S.R., et al. 2001. Normal human mammary epithelial cells spontaneously escape senescence and acquire genomic change. Nature. 409:633-637.
26. Blasco, M.A., et al. 1997. Telomere shortening and tumor formation by mouse cells lacking telomerase RNA. Cell. 91:25-34.

27. Kyo, S., et al. 2000. Sp1 cooperate with c-Myc to activate transcription of the human telomerase reverse transcriptase gene (hTERT). Nucleic Acids Res. 28:669-677.

28. Wu, K.J., et al. 1999. Direct activation of TERT transcription by c-MYC. Nat. Genet. 21:220-224.

29. Osthus, R.C., et al. 2000. Deregulation of glucose transporter 1 and glycolytic gene expression by c-Myc. J. Biol. Chem. 275:21797-21800.

30. Courey, A.J., and Tijan, R. 1988. Analysis of Sp1 in vivo reveals multiple transcriptional domains, including a novel glutamine-rich activation motif. Cell. 55:887-898.

31. Leggett, R.W., Armstron, S.A., Barry, D., and Mueller, C.R. 1995. Sp1 is phosphrylated and its DNA binding activity down-regulated upon terminal differentiation of the liver. J. Biol. Chem. 270:25879-25884.

32. Wick, M., Zubov, D., and Hagen, G. 1999. Genomic organization and promoter characterization of the gene encoding the human telomerase reverse transcriptase (hTERT). Gene. 232:97-106.

33. Xu, D., et al. 2000. Downregulation of telomerase reverse transcriptase mRNA expression by wild type p53 in human tumor cells. Oncogene. 19:5123-5133.

34. Ammendola, R., Mesuraca, M., Russo, T., and Cimino, F. 1994. The DNA-binding efficiency of $\mathrm{Sp} 1$ is affected by redox changes. Eur. J. Biochem. 225:483-489.

35. Majello, B., De Luca, P., Suske, G., and Lania, L. 1995. Differential transcriptional regulation of c-myc promoter through the same DNA binding sites targeted by Sp1-like proteins. Oncogene. 10:1841-1848.

36. Greenberg, R.A., et al. 1999. Short dysfunctional telomeres impair tumorigenesis in the INK4a $\mathrm{a}^{\Delta 2 / 3}$ cancer-prone mouse. Cell. 97:515-525.

37. Chin, L., et al. 1999. p53 deficiency rescues the adverse effects of telomere loss and cooperates with telomere dysfunction to accelerate carcinogenesis. Cell. 97:527-538. 